Mr Anđelko Gajić, dipl. inž.

\section{Snabdevanje letilice električnom energijom varijabilne frekvencije}

\section{Uvod}

Za napajanje različitih uređaja električnom energijom na savremenim letilicama koriste se izvori jednosmerne i naizmenične struje.

Oba vida električne energije imaju svoje prednosti i nedostatke, ali se na letilicama prednosti ovih vidova energije uzajamno dopunjuju.

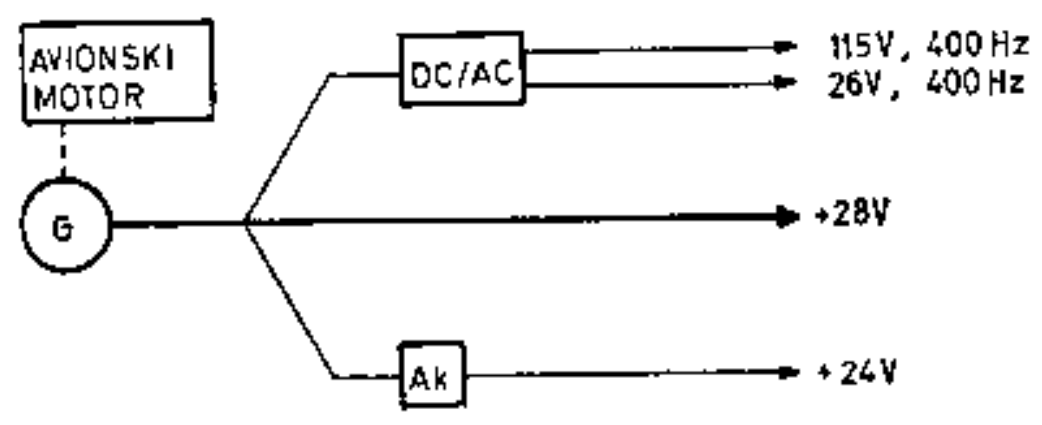

Sl. 1 Strukturna కema sistema napajanja jednosmernom strujom:

G - generator; DC/AC - statičkl pretvarač $2 \mathrm{BV} /$ I15V, $400 \mathrm{~Hz} ;$ Ak - akumtlator.

Osnovna prednost izvora jednosmerne struje (sl. 1) ogleda se u mogućnosti paralelnog rada jednog ili više generatora sa akumulatorima, što povećava pouzdanost celokupnog sistema napajanja i zahteva manju snagu ugrađenih generatora [1].

Druge prednosti sistema jednosmerne struje niskog napona $28 \mathrm{~V}$ su:

- veliki startni momenat jednosmernih motora; tiljki;

- male dimenzije i potrošnja sve-

- relativno jednostavan rad kontaktnih uređaja;

-- ne zahteva se sinhronizacija rada generatora.

Zahtevana pouzdanost sklopa kolektor-četkice na velikim visinama (pri niskom atmosferskom pritisku) dostignuta je.

$\mathrm{U}$ nedostatke jednosmernih niskonaponskih mreža ubrajaju se veliki preseci magistralnih provodnika i njihova masa. Isto tako, potrebni su veliki kontaktni uređaji i spajači.

Pomenuti nedostaci izvora i mreža jednosmerne struje, kao i ogranicene mogućnosti transformacije napona, uslovili su traganje za drugim vidovima napajanja. U prvom redu, rešenje je nađeno u izvorima i mrežama naizmenixne struje sa beskontaktnom komutacijom. Drugi pravac razvoja orijentisan je na primenu poluprovodnickih elemenata za poboljšanje karakteristika jednosmernih sistema napajanja.

U vazduhoplovstvu stalno postoji tendencija porasta broja i vrsta potrošača električne energije, kako jeđnosmerne, tako i naizmenične struje.

Mnogi radio-uređaji i sistemi letilice, u principu, zahtevaju koriscenje naizmeničnog monofaznog i trofaznog napajanja. 
Osnovne prednosti sistema napajanja naizmeničnom strujom nad sistemom jednosmerne struje ogledaju se u sledećem:

- jednostavna transformacija napona;

- mogućnost ispravljanja;

- odsustvo kolektora na mašinama;

- moguénost dostizanja visokih napona;

- ušteda na masi provodnika;

- relativno manja masa generatora naizmenične struje (alternatora).

Odsustvo kolektora i četkica na alternatoru znatno doprinosi povećanju pouzdanosti sistema napajanja [3].

U periodu korišćenja cevne tehnike izvori naizmenične struje bili su gotovo nezamenjivi zbog potrebe napajanja visokim naponom. Isto tako, mnogi analogni i sinhrouređaji principski su zahtevali napajanja monofaznom $i$ trofaznom strujom $26 \mathrm{~V}, 400 \mathrm{~Hz}$ (sl. 2).

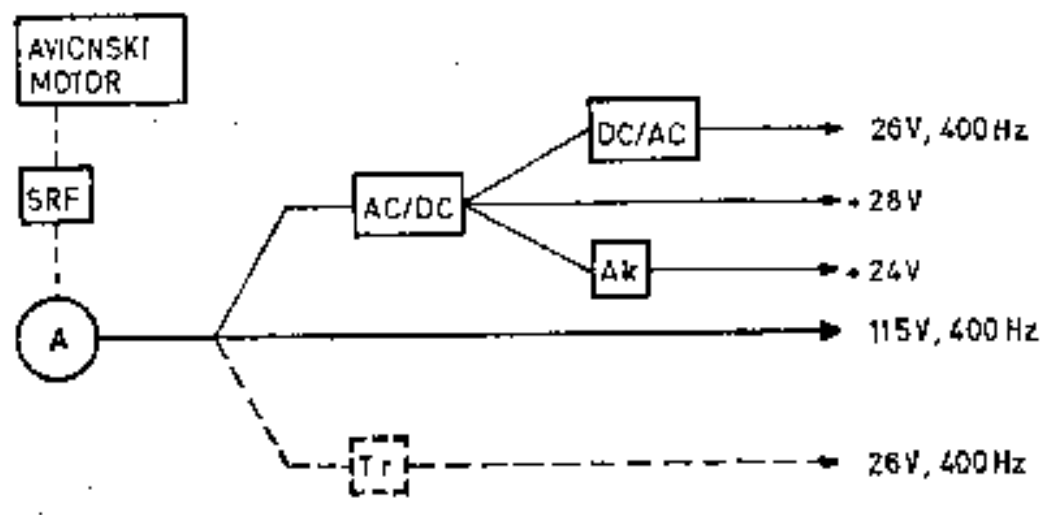

S1. 2 Strukturna Sema napajanja naizmeničnom strujom:

AC/DC - statıčki pretvarač 115V, 400Hz/28V; DC AC - staticki pretvarac $28 \mathrm{~V} / 26 \mathrm{~V}, 40 \mathrm{~Hz}$; $\mathrm{Tr}-$ transformator 115V/2BV (400Hz); SRF - sklop za regulaciju frekvencije; A - alternator.

Masovna primena niskonaponskih komponenata i digitalne elektronike u vazduhoplovstvu navela je na razmišljanje da će jednosmerno napajanje 28 V zadovoljiti gotovo sve potrebe. Međutim, neke prednosti naizmeničnog napajanja su neosporne i ono se zadržalo do danas sa tendencijom daljnjeg usavršavanja izvora i mreža.
Danas postoje letilice sa primarnim izvorima napajanja $28 \mathrm{~V}$ jednosmerne struje (generatori), ili $3 \times 115 \mathrm{~V}, 400 \mathrm{~Hz}$ (alternatori), ili sa oba sistema jednovremeno (sl. 3). Napajanje potrošača drugom vrstom struje rešava se putem konverzije u sekundarnim i tercijalnim izvorima. Vecina svetskih proizvođača vazduhoplovne elektronske opreme prilagođava se tržištu na taj način što nudi svoje uređaje sa ugrađenim modulom napajanja prema zahtevu kupca.

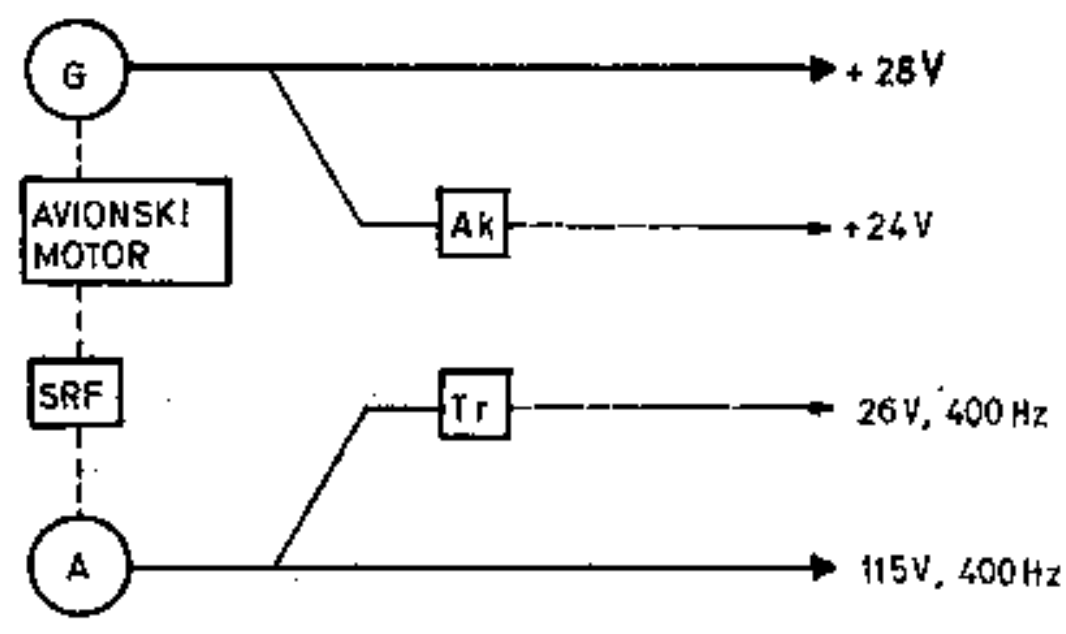

Sl. 3 Strukturna šema mesovitog napajanja: $\mathrm{SRF}-\mathrm{sklop}$ za regulactju Prekvenclje; Ak akumulator; $\operatorname{Tr}$ - transtormator; A - alternator; G - Eenerator.

Danas u svetskoj praksi postoji veći broj sistema električnog napajanja bez izgleda da-će neki od njih postati dominantan. Do nedavno se smatralo da je od svih sistema napajanja najperspektivniji sistem naizmenične struje stabilne frekvencije, prikazan na slici 2. Za optimalnu varijantu smatran je trofazni sistem $115 / 200 \mathrm{~V}, 400 \mathrm{~Hz}$, koji po mași bakarnih provodnika odgovara jednoprovodnom sistemu jednosmerne struje napona $120 \mathrm{~V}$ [4].

U složenim sistemima električnog napajanja na nekim letilicama takođe postoje podsistemi naizmeniêne struje sa neregulisanom (varijabilnom) frekvencijom. Alternatori takvih sistema imaju direktan pogon od motora letilice, te im se frekvencija menja u granicama od 400 do $900 \mathrm{~Hz}$. Kod ovakvih izvora vrši se samo stabilizacija napona na iznos $115 / 200 \mathrm{~V}$. Izvori ovog tipa nisu vezani ni za koji međuuređaj za re- 
gulaciju frekvencije (sl. 4). Iz ovih izvora vrši se napajanje većih potrošača letilice, koji imaju aktivnu impedansu, kao što su uređaji za odleđivanje i ostali grejaži [2].

- jednostavniji i pouzdaniji sistem napajanja;

- manja cena sistema;

- jeđnostavnije održavanje.

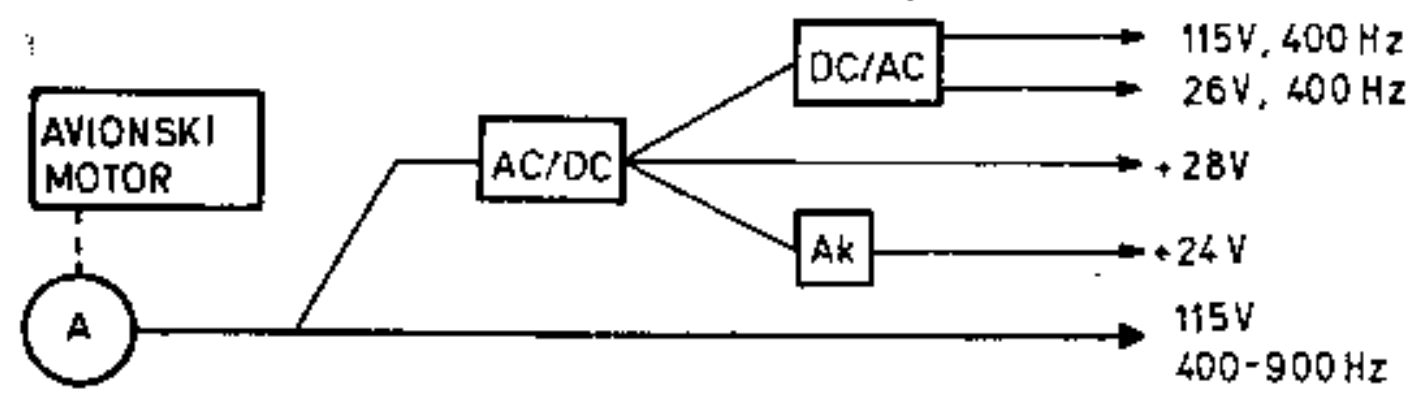

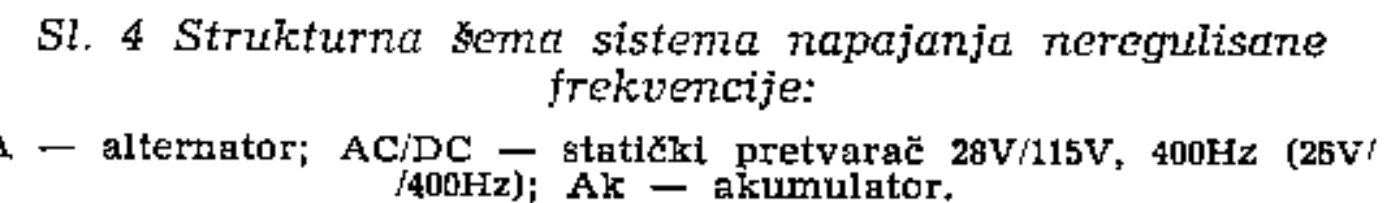

\section{Izvori i potrošači varijabilne frekvencije napajanja}

U poslednje vreme vrše se istraživanja mogućnosti prelaska na sisteme sa varijabilnom frekvencijom napajanja. Dakle, svi potrošači na letilici koji koriste napajanje naizmenicnom strujom treba da rade bez smetnji, ako je frekvencija napajanja varijabilna.

Ovakva razmatranja odnose se sqmo na one letilice koje imaju motore, cije vratilo ima promenljiv broj obrtaja u zavisnosti od režima rada.
Prelazak na sistem napajanja varijabilne frekvencije (sl. 5) zahteva preispitivanje svih elemenata sistema u pogledu: vljanja;

- kvaliteta transformacije $i$ ispra-

- naponsko-strujne zaštite;

- pouzdanost komponenata;

- vremena uključenja-isključenja u slučaju otkaza; trole);

- signalizacije (nadgledanja i kon-

- ispravnosti na zemIji i u letu;

- parametra koji se indiciraju posadi.

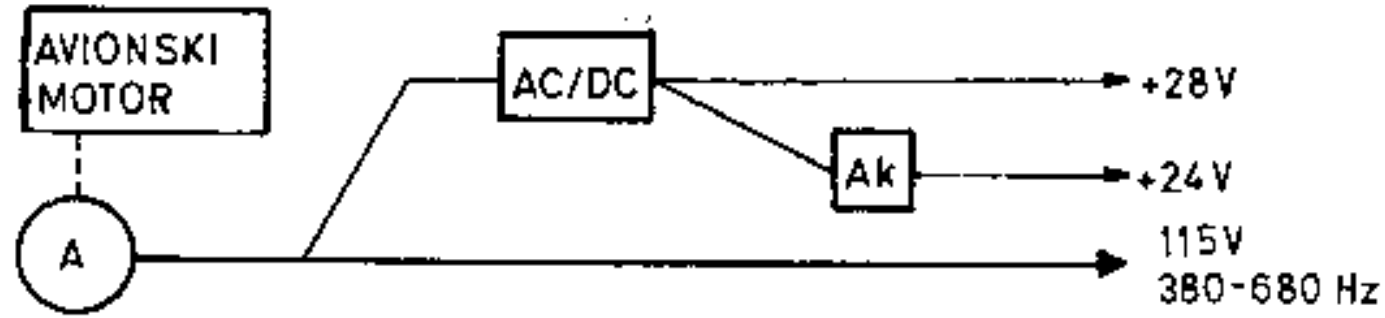

Sl. 5 Strukturna క̌ema sistema napajanja varijabilne frekvencije:

$\mathrm{A}$ - slternator; $\mathrm{AC} / \mathrm{DC}$ - statičiks pretvarac $115 \mathrm{~V}, 3 \mathrm{~B}-680 \mathrm{~Hz} 228 \mathrm{~V}$;

Ako se odabere sistem električnog napajanja sa alternatorom varijabilne frekvencije, mogu se očekivati sledeće dobiti:

- manja masa alternatora (umanjena za masu sklopa održanja konstantnog broja obrtaja);
Neosporno je da bi prelazak na izvore sa varijabilnom frekvencijom zahtevao promene na unutrašnjim izvorima napajanja pojedinih uređaja letilice.

Uvođenjem digitalne elektronike u opremu aviona znatno je opao interes za sinhroanalognim prenosom koji za- 
hteva dodatnu monofaznu ili trofaznu mrežu $26 \mathrm{~V}, 400 \mathrm{~Hz}$ stabilne frekvencije. Ako se u fazi projekta pokaže da pojedini uređaji na letilici ipak zahtevajt napajanje stabilnom frekvencijom, nastali problem se rešava uvođenjem pretvarača:

$28 \mathrm{~V}$ jednosmerni/115 V, $400 \mathrm{~Hz}$ (odnosno $26 \mathrm{~V}, 400 \mathrm{~Hz}$ ) ili $115 \mathrm{~V}, \mathbf{f}_{\mathrm{var}}$ ) $/ 115 \mathrm{~V}, \mathrm{f}_{\text {contst. }}$

gde je:

$f_{\text {var }}$-- varijabilna frekvencija, a

$f$

$U$ periodu prelaska na sistem varijabilne frekvencije biće sužen izbor opreme za ugradnju na letilice, dok proizvođači ne prilagode svoje uređaje na varijabilnu frekvenciju.

\section{Očekivane granice promene frekvencije}

Kod alternatora koji se pabuđuju sinhrono i pogone direktno od avionskog motora može se očekivati raspon promene radne frekvencije $f_{v a r}$. $u$ sledećim granicama:

$\mathrm{f}_{1}=380 \mathrm{~Hz}$ - za minimalnu brzinu obrtanja vratila,

$\mathrm{f}_{2}=680 \mathrm{~Hz}$ - $\mathrm{za}$ maksimalnu brzinu obrtanja vratila.

Odatle nalazimo da je raspon $\mathrm{f}_{\mathrm{var}}$ :

$$
\Delta \mathrm{f}=\mathrm{f}_{2}-\mathrm{f}_{\mathrm{i}}=300 \mathrm{~Hz}
$$

Ako se usvoji da je nominalna frekvencija $f_{10}=400 \mathrm{~Hz}$, kao za sisteme sa konstantnom frekvencijom, onda

$\Delta \mathrm{f}_{1}=\mathrm{f}_{\mathrm{t}}-\mathrm{f}_{\mathrm{n}}=-20 \mathrm{~Hz}$ a $\Delta \mathrm{f}_{2}=\mathrm{f}_{2}-\mathrm{f}_{\mathrm{n}}=$ $=280 \mathrm{~Hz}$

označavaju priraštaje frekvencije u toku rada. Iste promene $\mathrm{u}$ procentima iznose:

$\Delta \mathrm{f}_{1} / \mathrm{f}_{\mathrm{II}}=-20 / 400=-0,05$, odnosno $-5 \%$ i

$\Delta \mathrm{f}_{2} / \mathrm{f}_{\mathrm{n}}=280 / 400=0,70$, odnosna $\div 70 \%$.

\section{Uticaj promene frekvencije na rad električnih mašina}

Poseban problem se javlja kod obrtnih mašina kod kojih se napajanje vrsi naizmeničnom strujom varijabilne frekvencije, jer su bile projektovane za rad na konstantnoj frekvenciji. Problem je prisutan i kod transformatora čije su karakteristike proračunate za jednu frekvenciju ili uzan pojas frekvencija.

Napajanje varijabilnom frekvencifom izaziva najveće probleme kod potrošača veće snage, kao što su elektromotori gorivnih pumpi, motori za ventilaciju i transformatori.

$\mathrm{Na}$ nižim frekvencijama smanjuje se ukupna impedansa potrošača, što izaziva povećanje struje i dodatno zagrevanje.

Na višim frekvencijama takođe dom lazi do pregrevanja, ali zbog povećanih gubitaka u limovima. Dakle, na graničnim frekvencijama prisutna je promena potrošnje i adstupanje karakteristika od propisanih.

Kod motora male potrośnje, kao što su motori ventilatora, za pojedine elektronske uređaje ne očekuju se veći problemi, jer ih ventilatori tokom rada rashlađuju.

$\mathrm{Da}$ bi izlazne karakteristike elektrixnih mašina ostale u dozvoljenim granicama, neophodni su ponovni proračuni i neke dorade. Ove izmene u konstrukciji neminovno vode ka povećanju mase od 10 do $50 \%$ po jedinici. Ukupan priraštaj mase pomenutih uređaja može biti veći nego dobit nastala skidanjem sklopa za regulaciju frekvencije na alternatoru, što ide u prilog mišljenju da sistem varijabilne frekvencije neće u dogledno vreme ući u širu upotrebu.

\section{Uticaj promene frekveneije na rad elektronske opreme}

Polazeći od činjenice da elektronski uređaji koriste jednosmerne napone za napajanje, koji se obezbeđuju preko 
ispravljača, može se očekivati da će promena frekvencije primarnog napajanja uticati na karakteristike napona i struje koje daje ugrađeni blok napajanja.

Svaki transformator je proračunat za rad na određenoj frekvenciji, ređe u pojasu frekvencija. Diodni ispravljači i filtri takođe reaguju na promene frekvencije koje stabilizator napona ne može da kompenzira.

Ako se izvrši ispitivanje gotove opreme, koja je projektovana za $115 \mathrm{~V} /$ $1400 \mathrm{~Hz}$, na izvoru $115 \mathrm{~V}$ varijabilne frekvencije mogu se očekivati sledeći rezultati:

1. Uređaji koji u toku ispitivanja pokažu da u njihovom radu ne postoji nikakvo merljivo odstupanje u pogledu radnih karakteristika mogu biti uključeni, kako na izvore sa konstantnom, tako i na izvore sa varijabilnom frekvencijom. Kod uređaja ove grupe na njihovim izvorima (ispravljacima) nisu potrebne nikakve prepravke ili dorade, jer su prethodno dimenzionisani sa vecom rezervom.

2. Oprema kod koje prelazak na napajanje varijabilnom frekvencijom izaziva manje promene izlaznog napona i neznatno smanjuje pouzdanost sopstvenog izvora napajanja, ali se ta degradacija može smatrati zanemarljivom u apsolutnom iznosu ili u poređenju sa drugim uticajima. Dakle, pogoršanje karaketristika je u prihvatljivim granicama, tako da je intervencija na izvoru nepotrebna, a avaj uređaj može biti priključen na oba sistema napajanja bez štetnih posledica. Uređaji ove grupe takode ne zahtevaju prepravke ili dorade.

3. Oprema kod koje prelazak na varijabilnu frekvenciju izaziva nedopustivo velike promene napona na izlazu njihovog izvora, a ove promene remete rad uređaja ili znatno smanjuju pouzdanost izvora. Dodatno opterecenje kola ispravljača, filtra i stabilizacije u toj meri je izraženo da uređaj ne može biti priključn na ovaj sistem napajanja. Za prilagođenje ove opreme zahtevaju se novi izvori napajanja ili rekonstrukcija postojećih.

4. Uređaji koji principski ne dozvoIjavaju napajanje iz izvora varijabilne frekvencije:

- uređaji sa sinhrodavačima i prijemnicima;

- motori i generatori čije karakteristike znatno zavise od frekvencije napajanja;

- fazno i frekventno osetljivi detektori i releji.

Posledica prilagođenja pojedina厄̌nih uređaja na sistem napajanja sa varijabilnom frekvencijom može biti: nja;

- usložavanje šeme izvora napaja-

- ugradnja novih komponenata ilj samo pojačanje postojećih;

- neznatno povećanje mase;

- povećanje cene pojedinačno modifikovanih uređaja.

Ovako modifikovani uređaji mogu se koristiti u oba sistema napajanja.

\section{Optimizacija sistema napajanja}

Pouzdanost izvora električnog napajanja raste sa prelaskom na izvore varijabilne frekvencije. Odstranjivanjem sklopa za regulaciju frekvencije alternatora, u ekvivalentnoj šemi za proračun pouzdanosti sistema, smanjuje se broj serijski vezanih komponenata, tako da ukupna pouzdanost sistema raste.

Za sada je teško proceniti da li bi priraštaj pouzdanosti sistema mogao biti toliki da je moguće preći na jedan alternator u sistemima koji su iz razloga pouzdanosti bili izvedeni sa dva alternatora.

Kako pouzdanost pojedinačnih uređaja (potrošača), radi ove promene, neznatno opada ili ostaje nepromenjena, a pouzdanost sistema u celini takođe raste. 
Prelaskom na sistem varijabilne frekvencije acekuje se promena ukupne mase za iznos razlike mase sklopa za regulaciju frekvencije alternatora i ukupnog priraštaja mase od pojedinačnih elektro i elektronskih uređaja.

Ako se ostvari nejednakost

$$
M_{i}>\sum_{i} \wedge m_{i}
$$

gde je:

$\mathrm{M}_{\mathrm{r}}$ - masa sklopa za regulaciju frekvencije na alternatoru,

$\Delta \mathrm{m}_{\mathrm{i}}$ - priraštaj mase i-tog uređaja, onda prelazak na sistem varijabilne frekvencije ima pozitivan efekat u pogledu mase.

Odstranjivanjem sklopa za regulaciju frekvencije oslobađa se, takođe, prostor u veoma skučenom predelu agregata motora.

Od ostalih posledica prelaska na varijabilni sistem napajanja treba očekivati:

- manju cenu sistema;

- doprinos jednostavnijem održavanju;

- manji broj rezervnih stavki na skladištenju,

- manji broj ispitnih uređaja.

\section{Zaključak}

Prelazak sa sistema elektronapajanja konstantne frekvencije $400 \mathrm{~Hz}$ na sistem varijabilne frekvencije uslovljen je nizom problema praktične prirode.

\section{Literatura:}

[1] Tuzov, $v$. S.: »Elektrotehmecekije ustrojstva letateljnyh apparatov๔, Moskva; Vyss̆aja skola, $19 \$ 7$. [2] PaIlett, E. H. J.: Dircraft electrtcal systems
(second edition)e, Copthorne-Sussex, Pitman, 1979 .
Skidanje sklopa za regulaciju frekvencije alternatora radi prelaska na sistem varijabilne frekvencije ima sledece pozitivne posledice:

- smanjenje cene;

- smanjenje mase i zapremine;

- povećanje pouzdanosti sistema;

- manji broj rezervnih delova $i$ ispitnih uređaja;

- jednostavnije održavanje alternatora, odnosno sistema u celini.

Neophodno je, takođe, da se elektronski uređaji pre ugradnje prethodno ispitaju kako bi se sagledalo da li u pogledu radnih karakteristika i pouzdanosti postoje ograničnja. Oprema koja primetno gubi na karakteristikama pri prelasku na napajanje varijabilnom frekvencijom treba da se na adekvatan način promeni i doradi.

Oprema koja je sposobna da radi u sistemu varijabilne frekvencije može da radi bez ograničenja i u sistemu konstantne frekvencije.

Oprema koja se zasniva na sinhroanalognom principu nije prihvatlijiva za sisteme sa varijabilnom frekvencijom. Ako i bude zahteva za ugradnjom takve opreme, problem se može rešiti uvođenjem statičkih pretvarača $\mathrm{f}_{\mathrm{var}} / \mathrm{f}_{\text {const }}$ ili 28 $V$ jednosmerne struje/115 V, $400 \mathrm{~Hz}$ (ili $26 \mathrm{~V}, 400 \mathrm{~Hz}$ ).

Ukoliko se pokaže đa sistem varijabilne frekvencije u celini ima bolje karakteristike u pogledu pouzdanosti, mase i cene, može se očekivati nastavak radova na ovoj problematici i sire uvođenje ovakvih sistema u upotrebu.

[3] Bruskin, D. E., Koroban, N. T., Morozovskij, V. T., Sindjejev, I. M., sumthin, V. A.: $>0 \mathrm{~s}-$ novy elektrooborudovanija letateljnyh apparatove, (drugi deo), Moskva, Vyoǎaja škola, 1978.

[4] Bruskin, D. E., Slndeev, 1, M.: sElektrosnabženle Letateljnyh apparatov*, Moskva, Vyssaja rkola, $198 \mathrm{~B}$. 